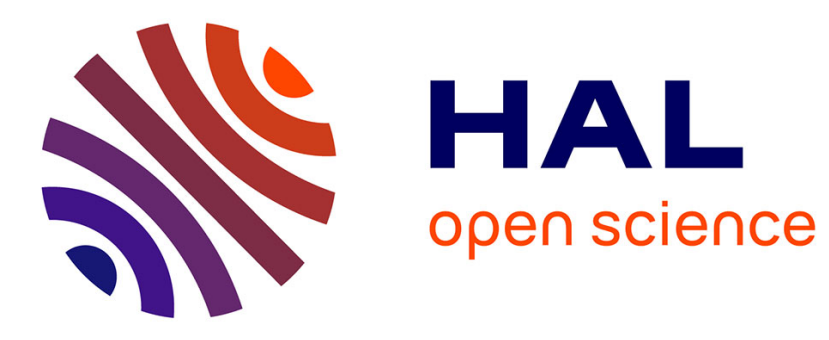

\title{
Role of Silver Nanoparticles in Enhanced Xenon Adsorption Using Silver-Loaded Zeolites
}

Ludovic Deliere, Sylvain Topin, Benoit Coasne, Jean-Pierre Fontaine, Sophie de Vito, Christophe den Auwer, Pier Lorenzo Solari, Cecile Daniel, Yves Schuurman, D. Farrusseng

\section{To cite this version:}

Ludovic Deliere, Sylvain Topin, Benoit Coasne, Jean-Pierre Fontaine, Sophie de Vito, et al.. Role of Silver Nanoparticles in Enhanced Xenon Adsorption Using Silver-Loaded Zeolites. Journal of Physical Chemistry C, 2014, 118 (43), pp.25032-25040. 10.1021/jp507590a . hal-01138386

\section{HAL Id: hal-01138386 https://hal.science/hal-01138386}

Submitted on 29 Jul 2021

HAL is a multi-disciplinary open access archive for the deposit and dissemination of scientific research documents, whether they are published or not. The documents may come from teaching and research institutions in France or abroad, or from public or private research centers.
L'archive ouverte pluridisciplinaire HAL, est destinée au dépôt et à la diffusion de documents scientifiques de niveau recherche, publiés ou non, émanant des établissements d'enseignement et de recherche français ou étrangers, des laboratoires publics ou privés.

\section{(c)(1)}

Distributed under a Creative Commons Attribution| 4.0 International License 


\title{
Role of Silver Nanoparticles in Enhanced Xenon Adsorption Using Silver-Loaded Zeolites
}

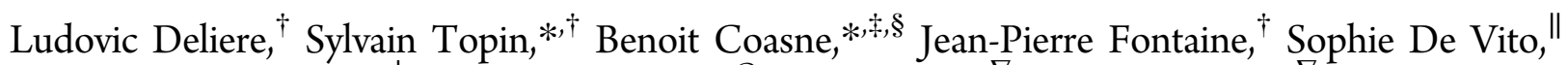 \\ Christophe Den Auwer, ${ }^{\perp}$ Pier Lorenzo Solari, ${ }^{\circledR}$ Cécile Daniel, ${ }^{\nabla}$ Yves Schuurman, ${ }^{\nabla}$ and David Farrusseng ${ }^{\nabla}$ \\ ${ }^{\dagger}$ CEA, DAM, DIF, F-91297 Arpajon Cedex, France \\ ${ }^{\ddagger}$ MultiScale Materials Science for Energy and Environment, CNRS and Massachusetts Institute of Technology, 77 Massachusetts \\ Avenue, Cambridge, Massachusetts 02139, United States \\ ${ }^{\S}$ Department of Civil and Environmental Engineering, Massachusetts Institute of Technology, 77 Massachusetts Avenue, Cambridge, \\ Massachusetts 02139, United States \\ "CEA, DAM, Le Ripault, B.P.-16, F-37260 Monts, France \\ ${ }^{\perp}$ Université Nice Sophia Antipolis, Institut de Chimie de Nice, UMR 7272, F-06108 Nice, France \\ ${ }^{\circledR}$ Synchrotron SOLEIL, L’Orme des Merisiers, Saint Aubin BP 48, F-91192 Gif-sur-Yvette Cedex, France \\ ${ }^{\nabla}$ IRCELYON, Université Lyon 1, CNRS, - 2, Avenue Albert Einstein, F-69626 Villeurbanne, France
}

\begin{abstract}
Molecular simulation is used to unravel the adsorption mechanisms of xenon on Ag-doped ZSM-5 zeolite. We show that silver nanoparticles, which form at the external surface of zeolite crystallites, are responsible for enhanced xenon physisorption at very low pressure. We also propose a simple model of adsorption on such composite materials made up of silver-exchanged zeolites and silver nanoparticles adsorbed at the zeolite surface. This model, which allows predicting the adsorption of other gases without any additional parameters, provides a tool to characterize the amount of reduced silver as well as the silver particle size distribution (in good agreement with transmission electron microscopy images). The presence of a majority of silver nanoparticles is further characterized by means of X-ray diffraction and X-ray Absorption Spectroscopy at the silver K edge.
\end{abstract}

\section{INTRODUCTION}

Xenon is a noble gas which is used in various applications such as energy efficient lighting, ${ }^{1}$ medicine, ${ }^{2}$ chemical analysis, ${ }^{3}$ etc. Several unstable Xe isotopes, which are produced by nuclear activities, are also used to monitor radioactive release into the air, especially in the context of the Comprehensive nuclear Test Ban Treaty (CTBT). ${ }^{4-6}$ Such monitoring employs porous adsorbents to capture, separate each noble gas and concentrate xenon. ${ }^{4,7}$ Given that xenon is the least abundant noble gas after radon (the atmospheric Xe concentration is $0.087 \mathrm{ppm}$ ), adsorbents with large xenon adsorption affinities (i.e., large heat of adsorption) are required to design efficient processes.

In the early 70s, Barrer and co-workers reported xenon adsorption isotherms in the atmospheric pressure range and showed that xenon is strongly adsorbed when the zeolite cation is exchanged with silver. ${ }^{9-11}$ Later, Munakata et al. ${ }^{12}$ investigated the possible use of silver-exchanged zeolites instead of activated carbons for xenon and krypton capture in the framework of the PUREX process (reprocessing of spent nuclear fuel). More recently, xenon adsorption isotherms at low pressure $(\sim 100 \mathrm{ppm})$ were reported for zeolite $5 \mathrm{~A},{ }^{13}$ zeolite $\mathrm{Y}^{14}$ chabazite, SAPO-34, and ALPO-CHA. ${ }^{15}$ The isosteric heat of adsorption of xenon on Ag-exchanged and Na-zeolites ( $\mathrm{Y}$ form) were found to be -31.0 and $-18.5 \mathrm{~kJ} \mathrm{~mol}^{-1}$, respectively. The beneficial effect of silver loading was also observed for zeolites such as Ag-modernite, ${ }^{12}$ Ag-ETS-10, ${ }^{16}$ AgChabazite, and Ag-ZSM-5. ${ }^{17}$ Very recently, Daniel et al. ${ }^{18}$ realized a screening of diverse silver-loaded zeolites for xenon capture at very low pressure $\left(0.1 \mathrm{ppm}=10^{-5} \mathrm{kPa}\right)$. These authors observed that silver-loaded zeolites present either one or two adsorption sites depending on the zeolite framework type and the silver loading. The heats of adsorption of xenon corresponding to the strongest adsorption site are -35 and -40 kJ mol ${ }^{-1}$ for AgX and Ag@ZSM-5, respectively. These strong adsorption sites were found to allow efficient xenon capture at very low pressure ( 0.1 to $100 \mathrm{ppm}$ corresponding to pressures $10^{-5}$ to $\left.10^{-2} \mathrm{kPa}\right)$.

The strong interaction between xenon and silver-exchanged zeolite was qualitatively explained using xenon nuclear magnetic resonance (NMR); ${ }^{19,20}$ such a strong adsorption arises from 
the specific interaction between xenon and the silver cations in the zeolite supercages. Recently, a density functional theory (DFT) study by Nguyen et al. ${ }^{21}$ on the binding between xenon and silver cluster $\left(A g_{n}^{+}\right.$with $\left.n=1-4\right)$ suggested that strong xenon adsorption occurs rather on silver clusters than on neutral silver particles. However, significant discrepancies were observed between the theoretical $(-14 \mathrm{~kJ} / \mathrm{mol})$ and experimental (approximately $-30 \mathrm{~kJ} / \mathrm{mol}$ ) adsorption energies. In contrast, Kuznicki et al. ${ }^{16}$ have hypothetically attributed the strong adsorption on Ag-ETS-10 to a specific interaction of xenon with silver nanoparticles observed at the external surface of zeolite grains. Furthermore, the heats of adsorption reported for Ag-ETS-10 are between 40 and $90 \mathrm{~kJ} \mathrm{~mol}^{-1}$, which are the largest values reported for xenon physisorption. It is wellknown that heat treatment of silver-exchanged zeolites causes the reduction of silver ions $\mathrm{Ag}^{+}$to silver nanoparticles (noted AgNPs in what follows) and/or silver cluster. ${ }^{22,23}$ The formation of silver nanoparticles is also observed in zeolite with small-pore such as Ag-natrolite. ${ }^{24}$ This autoreduction was also reported in metal-organic frameworks (MOFs) such as Ag@MOF-74Ni. ${ }^{25}$ In this study, the authors have reported that silver nanoclusters are likely responsible for the large xenon uptake, although the adsorption mechanism was not determined.

In summary, the mechanisms proposed in the literature, which rely both on experimental and theoretical data, are somewhat contradictory and the nature of the adsorption sites in silver-loaded zeolites is still an open question. Moreover, the strongest adsorption sites, which have been recently discovered for Ag-loaded ZSM-5, BEA, and Faujasite X, have not been studied in detail. ${ }^{18}$ The characterization of these very strong sites is of the utmost importance as it would enable designing efficient adsorbents for the capture of atmospheric xenon. Beyond the identification of the nature of these strongest sites, unraveling the adsorption mechanism is even more complex because no characterization techniques allow quantifying the different types of silver in conditions relevant to the practical application: $\mathrm{Ag}^{+}$cations, charged $\mathrm{Ag}$ clusters, $\mathrm{Ag}_{2} \mathrm{O}$ particles, and $\mathrm{Ag}$ particles.

Our previous screening of Ag-zeolite has shown that the largest number of strong adsorption sites is obtained for $10.5 \mathrm{wt}$ $\%$ Ag-loaded ZSM-5. ${ }^{18}$ In the present paper, we provide an indepth study of this sample with the aim to determine the origin of the strong adsorption sites responsible for such enhanced xenon capture. We demonstrate by means of a combined experimental and theoretical study that silver nanoparticles are responsible for xenon physisorption at very low pressure $\left(10^{-5}\right.$ $\mathrm{kPa} \sim 0.1 \mathrm{ppm})$ while $\mathrm{Ag}^{+}$adsorption sites adsorb xenon at larger pressures. The presence of a large amount of $\mathrm{Ag}$ nanoparticles (AgNPs) is characterized using X-ray diffraction (XRD), X-ray absorption near edge structure (XANES), extended X-ray absorption fine structure (EXAFS), and transmission electronic microscopy (TEM). Using Grand Canonical Monte Carlo simulations, we provide a simple yet quantitative tool to estimate the numbers of AgNPs and $\mathrm{Ag}^{+}$ adsorption sites. This paper also reports a simple model of adsorption on such composite materials made up of silverexchanged zeolites and silver nanoparticles adsorbed at the external zeolite surface. We derive a simple equation which allows describing adsorption on such systems and test it against molecular simulations. We also apply it to our experimental data and show that it allows retrieving the nanoparticle size distribution seen from TEM experiments. Finally, we further validate this model by showing that it also allows predicting krypton adsorption data on the same system without any additional parameters.

\section{EXPERIMENTAL AND COMPUTATIONAL DETAILS}

2.1. Experimental Methods. The adsorbents used in this work were prepared from a commercial Na-ZSM-5 zeolite. Silver was loaded using a classical exchange procedure starting from sodium zeolites. The sodium zeolite powder Na-ZSM-5 was suspended in an aqueous solution of $\mathrm{AgNO}_{3}$. The mixture was stirred and the powder filtered, washed several times with deionized water, and dried at $373 \mathrm{~K}$. Finally, the powder was treated at $673 \mathrm{~K}$ under $\mathrm{N}_{2}$ (BIP purity) gas flow in order to thermally stabilize the adsorbents for their use in further experiments.

The silver loading was measured by ICP-OES (inductively coupled plama-optical emission spectrometry). The XRD powder diffraction patterns, which were recorded at $2 \theta$ between $10^{\circ}$ and $100^{\circ}$ with $\mathrm{Cu} \mathrm{K} \alpha(\lambda=1.5406 \AA)$, were used to show the presence of silver nanoparticles and to verify their crystalline structure. X-ray absorption spectroscopy (XAS) experiment on the Ag K-edge $(25514 \mathrm{eV})$ have been performed at the MARS beamline at SOLEIL Synchrotron (Saclay, France) to analyze the silver phase and its oxidation state. Energy calibration of the monochromator has been carried out with an $\mathrm{Ag}$ metallic foil at $25514 \mathrm{eV}$. To analyze the silver phase and its oxidation state, X-ray absorption spectroscopy (XAS) measurements at the Ag K-edge have been performed in transmission mode at the MARS beamline of the SOLEIL Synchrotron (Saint-Aubin, France). ${ }^{26}$ The optics of the beamline were set by using the two silicon (220) crystals for the monochromator and the platinum strips at an angle of 2.2 mrad for the reflecting mirrors. Energy calibration of the monochromator has been carried out by measuring the K-edge of an $\mathrm{Ag}$ metallic foil (edge at $25514 \mathrm{eV}$ ). Data were processed using the Athena-Artemis chain of codes. ${ }^{27}$ Background removal was performed using a pre-edge linear function and the AUTOBK algorithm. The EXAFS data and corresponding Fourier transform (FT) were computed in $\mathrm{k}^{2} \chi(\mathrm{k})$ between 1.9 and $11.3 \AA^{-1}$. Phases and amplitudes were calculated by the Feff84 code from the AgO structure. ${ }^{28}$ Fitting was carried out in the simple scattering formalism in $\mathrm{R}$ space without any filtering of the data between 1 and $4 \AA$. The $\mathrm{R}$-factor is provided as an indication of the fit quality in $\mathrm{R}$ space. The size distribution of the silver nanoparticles was assessed by means of TEM (JEOL). Image analysis was performed for about 300 silver nanoparticles with ImageJ. ${ }^{29}$ High-resolution TEM showing Ag cluster/particles of less than 10 atoms were carried out on a TITAN G2 (FEI).

The xenon and krypton adsorption isotherms were carried out at $303 \mathrm{~K}$ using a volumetric apparatus from Belsorp-Max (Bel Japan) with 4.8 grade xenon and 4.8 grade krypton (Messer). Prior to the measurements, the samples were treated under a vacuum of $5.10^{-5} \mathrm{~Pa}$ at $573 \mathrm{~K}$ for $12 \mathrm{~h}$. The noble gas uptake was measured at pressures ranging from $10^{-5} \mathrm{kPa}(0.1$ $\mathrm{ppm})$ to $100 \mathrm{kPa}$. When reporting adsorption isotherms, the noble gas pressure was plotted using a log scale in order to better visualize the uptakes over the whole pressure range (from $\mathrm{ppm}$ to the atmospheric pressure). Adsorption equilibrium was assumed to be reached when the pressure variation over an equilibration time of $300 \mathrm{~s}$ is less than $0.3 \%$. For long measurement times, variation of the level of the regulated water bath and thus the change of dead volume needs 
to be taken into account. Consequently, all measurements were carried out using the high-accuracy mode available on the Belsorp Max device. This unique method, AFSM (advanced free space measurement), compensates the free space change in the sample cell. This is done by measuring the pressure change in a separate empty sample cell.

2.2. Molecular Simulation. Zeolites, Silver Nanoparticles, and Composite Systems. The zeolite framework ZSM-5 was obtained from the silicalite-1 structure whose chemical composition is $\mathrm{Si}_{96} \mathrm{O}_{192}$. ZSM-5 is a specific zeolite material that belongs to the MFI family/structure in the zeolite database. This zeolite structure is made up of 10 -membered ring channels (10-MR). The unit cell was duplicated in the $z$ axis direction in order to have a bigger system size with $x, y$, and $z$ equal to $20.07,19.92$, and $26.84 \AA$, respectively. To mimic a silver-exchanged zeolite Ag@ZSM-5 with a ratio Si/Al = 12 in a realistic way, $N=15$ silicon atoms were substituted with aluminum atoms. Following previous works, ${ }^{30}$ the substitutions were attempted randomly but we checked that they respect Lowenstein's rule. ${ }^{31}$ The charge defect induced by the $\mathrm{Si}$ to $\mathrm{Al}$ substitutions was compensated by adding $N$ silver ions $\mathrm{Ag}^{+}$to obtain a model of Ag-ZSM-5 (Figure 1) with a chemical

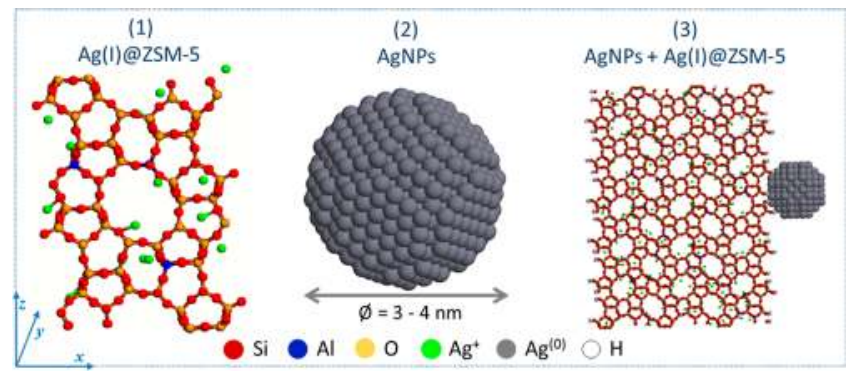

Figure 1. Structural model of silver-exchanged zeolite ZSM-5 with a $\mathrm{Si} / \mathrm{Al}$ ratio equal to 12 (left), structural model of silver nanoparticles (center), and composites made up of ZSM-5 with silver nanoparticles adsorbed at the external surface (right).

formula $\mathrm{Ag}_{15} \mathrm{Si}_{177} \mathrm{Al}_{15} \mathrm{O}_{384}$. During the simulation, the zeolite framework was considered rigid to reduce the computational burden except for the extra framework silver cations which were allowed to move. For small molecules, this assumption has been shown to be reasonable. ${ }^{32}$ The charges on the $\mathrm{Si}, \mathrm{O}$, and $\mathrm{Al}$, which were taken from the work by Van Beest et al., ${ }^{33}$ are $q_{\mathrm{Si}}=$ $2.4 e, q_{\mathrm{O}}=-1.2 e$, and $q_{\mathrm{Al}}=1.4 e$. The charge for the silver cations was fixed at $q_{\mathrm{Ag}}=+1 \mathrm{e}$. A spherical cutoff radius has been set at $9 \AA$ (i.e., about half the smallest size of the simulation box) for truncating the Lennard-Jones interactions. Periodic boundary conditions were applied in the $x, y$, and $z$ directions to avoid finite size effects. The electrostatic interactions were calculated with the Ewald summation technique to correct for the finite size of the system (the Ewald sum parameters were selected to obtain an accuracy $10^{-5}$ ).

Silver nanoparticles were built from a large face-centered cubic (FCC) structure of crystalline silver with a lattice parameter equal to $4.0853 \AA$ (Figure 1). Silver nanoparticles with a diameter of 3 and $4 \mathrm{~nm}$ were prepared. Each nanoparticle was then placed in a cubic simulation box at least twice larger than the nanoparticle (allowing multilayer adsorption of xenon at the particle surface). The silver nanoparticles are electroneutral since all atoms carry a charge equal to zero $\left(\mathrm{Ag}^{0}\right)$. The cutoff is set to half the size of the simulation box.
In this work, we also considered composite materials which are made up of $\mathrm{Ag}^{+}$cationic zeolites and $\mathrm{Ag}^{0}$ nanoparticles. The ZSM-5 framework $(\mathrm{Si} / \mathrm{Al}=12)$ was duplicated in the $x, y$, and $z$ axis directions. Such a larger system was placed in a simulation box of a larger size in the $x$ axis in order to mimic an external surface. A number $K$ of extraframework silver cations were substituted by hydrogen atoms (named $\mathrm{H} 1$ ), while the oxygen dangling bonds at the external surface along the $x$ axis were saturated by adding hydrogen atoms (named $\mathrm{H} 2$ ). The silver nanoparticles formed by the $K$ silver atoms were then placed at the external surface along the $x$ axis. The composite system (3) is made up of (1) a zeolite framework duplicated three times along the $x, y$, and $z$ axes and (2) $2 \mathrm{~nm}$ silver nanoparticles placed at the external surface of the zeolite (Figure 1 ). The final box size is $120.21 \times 59.46 \times 80.52 \AA$. The charges on the $\mathrm{Si}, \mathrm{Al}$, $\mathrm{O}$, and $\mathrm{Ag}$ were the same as those for the initial zeolite framework ZSM-5. For the silver nanoparticles, the atomic silver charge was null. To ensure the electroneutrality of the simulation box, the hydrogen atoms carry a charge $q_{\mathrm{H} 1}=+1 \mathrm{e}$ and $q_{\mathrm{H} 2}=+0.6 \mathrm{e}$ for $\mathrm{H} 1$ and $\mathrm{H} 2$, respectively. The cutoff distance was chosen equal to $29.7 \AA$.

Grand Canonical Monte Carlo Simulations. Xenon and krypton adsorption in the different systems presented above was simulated by means of Monte Carlo simulations in the Grand Canonical (GCMC). The Grand Canonical Monte Carlo algorithm ( $\mu \mathrm{VT}$ ensemble) is a stochastic method that simulates a system having a constant volume $V$ in equilibrium with an infinite reservoir of molecules. In this technique, the fictitious reservoir imposes its chemical potential, $\mu$, and temperature, T. Starting from an initial configuration, new configurations are generated by randomly displacing an existing molecule and by creating or deleting molecules within the simulation box. These new configurations are accepted or rejected in the framework of the Metropolis sampling scheme. ${ }^{34}$

Lennard-Jones (12-6) potentials were used to model the interaction between xenon (or krypton) and atoms of the zeolite framework. Following previous work, the noble gas atoms interact with the $\mathrm{O}$ atoms of the zeolite only (i.e., no interactions with the $\mathrm{Si}$ and $\mathrm{Al}$ atoms). ${ }^{35,36}$ Indeed, due to the large polarizability of oxygen compared to silicon and aluminum, it can be assumed that the interactions with these two species are screened by those with oxygen. ${ }^{36,37}$ The interaction between xenon and the silver ions and silver atoms in the nanoparticles were assumed to be identical. The charge difference between silver ion $(q=+1)$ and metal $(q=0)$ has no impact on the interaction with xenon since the latter is neutral. The polarizabilty terms of xenon were not included in our simulation. However, we checked that the simulated data for xenon adsorption with polarizability terms on silicalite- 1 and without polarizability are very similar (within $\pm 5 \%){ }^{38}$ The difference between the two sets of data is even smaller for krypton as krypton is less polarizable than xenon. While most interactions were taken from the literature, the $\mathrm{Xe}-\mathrm{Ag}, \mathrm{Xe}-\mathrm{H}$, $\mathrm{Ag}-\mathrm{H}, \mathrm{Si}-\mathrm{H}, \mathrm{Al}-\mathrm{H}$, and $\mathrm{O}-\mathrm{H}$ Lennard-Jones parameters were determined from the Lorentz-Berthelot combining rules (see Table 1). ${ }^{39,40}$ The same combining rules were used for krypton. Following previous work, we assumed that the dispersion/repulsion interaction parameters for $\mathrm{Si}$ and $\mathrm{Al}$ are identical. ${ }^{41}$ On the other hand, these two atoms in the zeolite have different partial charges so that their interactions with silver ions differ because of the Coulombic interaction.

Xenon and krypton adsorption on the silver nanoparticles, silver-exchanged zeolite ZSM-5, and the composite system was 
Table 1. Lennard-Jones (12-6) Parameters Used in This Work $^{a}$

$\begin{array}{llccc} & & \varepsilon(\mathrm{K}) & \sigma(\AA) & \text { ref } \\ \mathrm{Xe} & \mathrm{Xe} & 281.00 & 3.85 & 38 \\ \mathrm{Kr} & \mathrm{Kr} & 191.43 & 3.57 & 38 \\ \mathrm{Xe} & \mathrm{Ag} & 1060.04 & 3.19 & \mathrm{LB} \\ \mathrm{Kr} & \mathrm{Ag} & 874.9 & 3.06 & \mathrm{LB} \\ \mathrm{Xe} & \mathrm{O} & 135.87 & 3.45 & 35 \\ \mathrm{Kr} & \mathrm{O} & 95.97 & 3.30 & \mathrm{LB} \\ \mathrm{Xe} & \mathrm{H} & 46.37 & 3.19 & \mathrm{LB} \\ \mathrm{Kr} & \mathrm{H} & 38.27 & 3.22 & \mathrm{LB} \\ \mathrm{Ag} & \mathrm{Ag} & 3998.89 & 2.54 & 41 \\ \mathrm{Ag} & \mathrm{Si} & 1738.34 & 1.91 & 41 \\ \mathrm{Ag} & \mathrm{Al} & 1738.34 & 1.91 & - \\ \mathrm{Ag} & \mathrm{O} & 1999.44 & 1.88 & 41 \\ \mathrm{Ag} & \mathrm{H} & 174.95 & 2.54 & \mathrm{LB} \\ \mathrm{H} & \mathrm{H} & 7.65 & 2.85 & 42 \\ \mathrm{H} & \mathrm{Si} & 34.53 & 3.33 & \mathrm{LB} \\ \mathrm{H} & \mathrm{Al} & 34.53 & 3.33 & \mathrm{LB} \\ \mathrm{H} & \mathrm{O} & 19.19 & 2.94 & \text { LB }\end{array}$

${ }^{a} \mathrm{LB}$ indicates that the Lennard-Jones parameters were obtained from the like atoms parameters using the Lorentz-Berthelot combining rules.

studied in the pressure range from $10^{-6}$ to $100 \mathrm{kPa}\left(10^{-2}\right.$ to $10^{6}$ ppm). The chemical potential, $\mu$, for xenon is related to its fugacity, $f$ :

$$
f=\frac{k_{\mathrm{b}} T}{\Lambda^{3}} \exp \left(\mu / k_{\mathrm{b}} T\right)
$$

where $k_{\mathrm{B}}$ is Boltzmann's constant, $T$ the temperature, and $\Lambda$ the de Broglie thermal wavelength. In this work, xenon and krypton were treated as ideal gases so the pressure, $P$, is equal to the fugacity, $f$. Given the low pressures considered in this work, treating these gases as an ideal gas is a reasonable approximation. For all pressures, we used at least $5 \times 10^{7}$ Monte Carlo steps to equilibrate the system. The thermodynamics of adsorption was further investigated by analyzing the isosteric heat of adsorption Qst, which is related to the interaction between the adsorbate and adsorbent. ${ }^{43}$

$$
Q_{s t}=k_{\mathrm{b}} T-\frac{\left\langle U N_{\mathrm{ads}}\right\rangle-\langle U\rangle\left\langle N_{\mathrm{ads}}\right\rangle}{\left\langle N_{a d s}^{2}\right\rangle-\left\langle N_{\mathrm{ads}}\right\rangle^{2}}
$$

where $U$ is the energy and $N_{\text {ads }}$ the number of adsorbed molecules.

\section{RESULTS AND DISCUSSION}

3.1. Experimental Xenon Adsorption. The xenon adsorption isotherm at $303 \mathrm{~K}$ in Ag@ZSM-5 exhibits two adsorption steps: a first step at low pressure from $10^{-4}$ to $10^{-1}$ $\mathrm{kPa}$ (corresponding to adsorption on sites referred to as site II) and a second step at higher pressure (corresponding to adsorption on sites referred to as site I) (Figure 2). These two steps reveal the presence of two distinct adsorption sites with a first strong site (site II) at very low pressure. Both adsorption sites were previously characterized by fitting the experimental data using a double site Langmuir model. ${ }^{44}$ The number of strong sites (site II) was estimated to $5.7 \pm 0.5 \times 10^{-4} \mathrm{~mol} \mathrm{~g}^{-1}$ with a heat of adsorption of $-40 \pm 2 \mathrm{~kJ} / \mathrm{mol}$. On the other hand, the number of weak sites (site I) was estimated to $1.6 \pm$

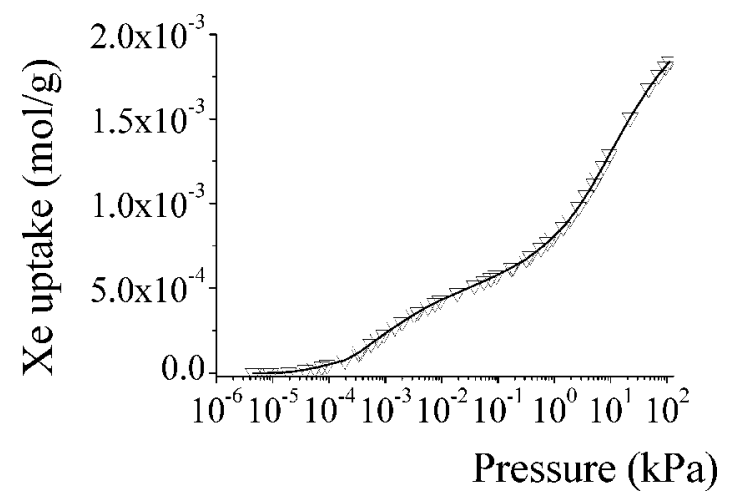

Figure 2. Xenon adsorption isotherm at $303 \mathrm{~K}$ on zeolite Ag loaded ZSM-5. Experimental isotherm (triangle down) and fit by a double-site Langmuir model (line). ${ }^{18}$

$0.1 \times 10^{-3} \mathrm{~mol} / \mathrm{g}^{-1}$ with a heat of adsorption at zero coverage of $-34 \pm 2 \mathrm{~kJ} / \mathrm{mol}$.

3.2. Characterization of the Structure of the Adsorbent. ICP-OES analysis of silver and sodium after the exchange process enables determining an exchange ratio $>99.9 \%(\mathrm{Ag}=10.5 \mathrm{w} \%$ and $\mathrm{Na}<0.1$ wt \%). TEM analysis, which was performed after the heat treatment under $\mathrm{N}_{2}$ flow, indicates that most of the silver has been reduced into silver nanoparticles (Figure 3, left). The particle size distribution,
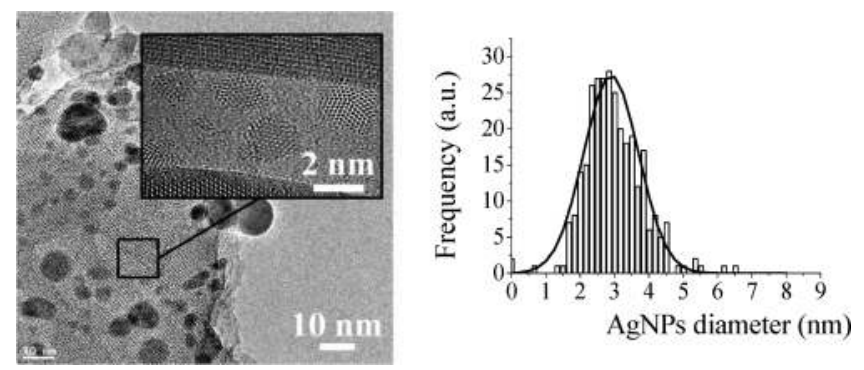

Figure 3. (left) TEM images of Ag@ZSM-5 showing the presence of silver nanoparticles. The inset shows high resolution-TEM images of small nanoparticles. (right) Diameter distribution of AgNPs extracted from the TEM images. The line is a fit using a Gaussian distribution.

which was fitted against a Gaussian distribution, reveals that the mean nanoparticle size is around $3 \mathrm{~nm}$ with a standard deviation around $0.8 \mathrm{~nm}$ (Figure 3, right). Note that because of the relatively high particles concentration into the TEM images, it is frequent that particles are overlapping although they are actually separated in the direction perpendicular to the image plane. As a consequence, the analysis of the TEM images leads to a non-negligible yet small overestimation of the actual particle size. Large Ag particles of a size $\sim 10 \mathrm{~nm}$ are also observed in the TEM images. Such very large particles, which are not shown in the particle size distribution in Figure 3, are thought to arise from the merging of smaller nanoparticles. Moreover, given the fact that their number/occurrence is low and their adsorption capacity (mol Xe/g), their impact on adsorption is assumed to be negligible. Most of the particles are larger than the ZSM-5 zeolites microporous channels $(d>5.5$ $\AA$ ), which demonstrates that they are not located in the zeolite microporous channels but most likely at the external surface of the zeolite crystallites. At high magnification, some small nanoparticles (around $\sim 0.7 \mathrm{~nm}$, made up of about 10 atoms) can be observed in the TEM images. Such particles are 
necessarily located at the external surface of the zeolite grains as the cavities in ZSM-5 have an internal diameter of about 0.5 $\mathrm{nm}$. In contrast, we note that smaller clusters (made up of 3-4 atoms) can be located in the zeolite cavities. The number of such small clusters present in the zeolite cavities cannot be quantified as they are too small to be observed using TEM at regular magnification. As a result, the particle size distribution shown in (Figure 3, right) does not take into account such intracrystalline clusters and therefore should be considered representative of clusters at the external zeolite surface only. Physisorption experiments could be used to probe the presence of such particles in the zeolite cavities. The fact that our simple model (eq 3), which describes adsorption in the system as the sum of adsorption in the zeolite cavities and adsorption at the surface of silver nanoparticles, reproduces the maximum adsorbed amount suggests that the zeolite cavities are free of silver particles.

The X-ray powder diffraction patterns of the parent $\mathrm{Na@}$ ZSM-5 and silver-loaded zeolite are shown in Figure 4. The

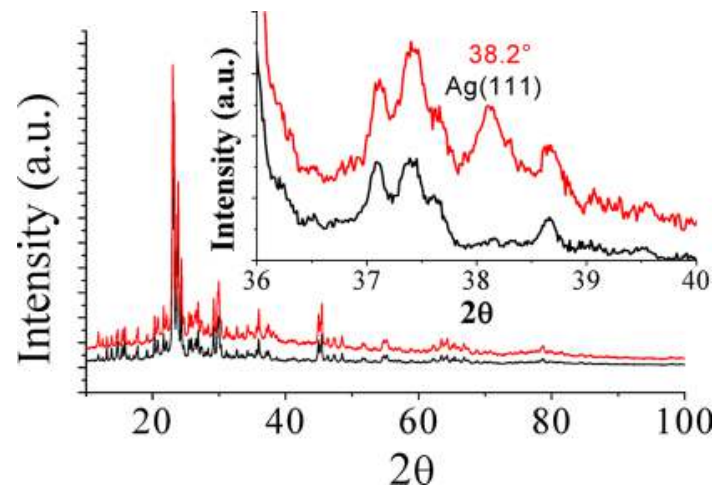

Figure 4. XRD patterns of Na@ZSM-5 (black) and Ag@ZSM-5 (red) with a zoom in the range $2 \theta=[36: 40]$ to visualize the peak characteristic of the silver phase FCC $\operatorname{Ag}(111)$.

diffraction peak at $2 \theta=38^{\circ}$, which corresponds to the 111 crystallographic planes of the face-centered cubic (fcc) silver

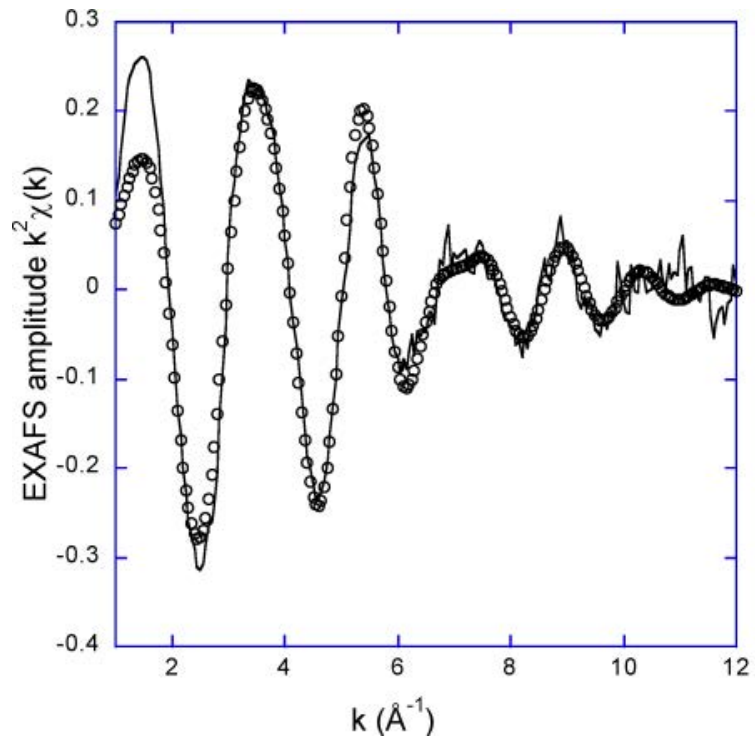

crystals (ICDD patterns ref: 00-004-0783) confirms the reduction of $\mathrm{Ag}^{+}$in silver metal particles under the thermal treatment in an inert gas stream. This observation is consistent with the work by Shi et al. ${ }^{22}$ who considered Ag-H-ZSM-5 zeolite treated at $500{ }^{\circ} \mathrm{C}$ under helium $(\mathrm{He})$ stream.

XAS is widely used to probe the local structure of materials, especially for amorphous or highly disordered structures. Figure 5 shows the experimental EXAFS spectrum and corresponding Invert Fourier Transform (IFT) of Ag@ZSM-5 at the K edge of Ag. The experimental IFT exhibits two main contributions at c.a. $\mathrm{R}+\Phi=1.6$ and $2.7 \AA$. Adjustment of the EXAFS signal in the real space with one contribution of $\mathrm{O}$ atoms and one contribution of $\mathrm{Ag}$ atoms lead to a good fit with $\mathrm{r}$ factor and metrical parameters described in Table 2 . The first contribution

Table 2. Metrical Best Fit Parameters of the Adjustment of the EXAFS Spectrum of Ag@ZSM-5 at the K Edge of $\mathrm{Ag}^{a}$

\begin{tabular}{lll}
\multicolumn{1}{c}{ sample } & \multicolumn{1}{c}{ O first contribution } & Ag second contribution \\
$\mathrm{Ag} @ \mathrm{ZSM}-5$ & $2.7(1) \mathrm{O}$ at $2.31(1) \AA$ & $0.8(1) \mathrm{Ag}$ at $2.79(2) \AA$ \\
EXAFS adjustement & $\sigma^{2}=0.0164 \AA^{2}$ & $\sigma^{2}=0.0155 \AA^{2}$ \\
$\mathrm{Ag}$ metal $^{48}$ & & $2.9 \AA$ \\
$\mathrm{AgO}^{49}$ & $2.03 \AA$ & $3.4 \AA$ \\
$\mathrm{Ag}_{2} \mathrm{O}^{50}$ & $2.04 \AA$ & $3.34 \AA$
\end{tabular}

${ }^{a}$ Numbers in parentheses give the uncertainties; $\sigma$ is the Debye Waller factor. The global amplitude factor S02 is equal to 1.0, the energy threshold $\mathrm{e} 0$ is equal to $5.41 \mathrm{eV}$, and the $r$ factor of the fit is equal to $1.6 \%$. For comparison, crystallographic distances from the literature are also given for $\mathrm{Ag} 2 \mathrm{O}, \mathrm{AgO}$, and $\mathrm{Ag}$ metal.

in the EXAFS signal is due to the $\mathrm{Ag}-\mathrm{O}$ contribution at a distance of $2.31 \AA$. This value is in good agreement with the typical values $(2.33 \AA)$ for the distance between silver cations and oxygen framework atoms in zeolites. ${ }^{45}$ The coordination number (2.7) is also close to the coordination obtained by Bordiga et al. ${ }^{45}(2.5 \mathrm{O}$ at $2.30 \AA$ for $\mathrm{Ag}-\mathrm{O})$ for $\mathrm{Ag}^{+}$in their zeolite material (Ag(I)-ZSM-5). Concerning the second contribution, the $\mathrm{Ag}-\mathrm{Ag}$ distance in Table 2 is $0.1 \AA$ shorter but of the same order as the first Ag distance in metallic $\mathrm{Ag}$ $(2.90 \AA)$. This suggests the presence of $\mathrm{Ag}^{0}$ species and

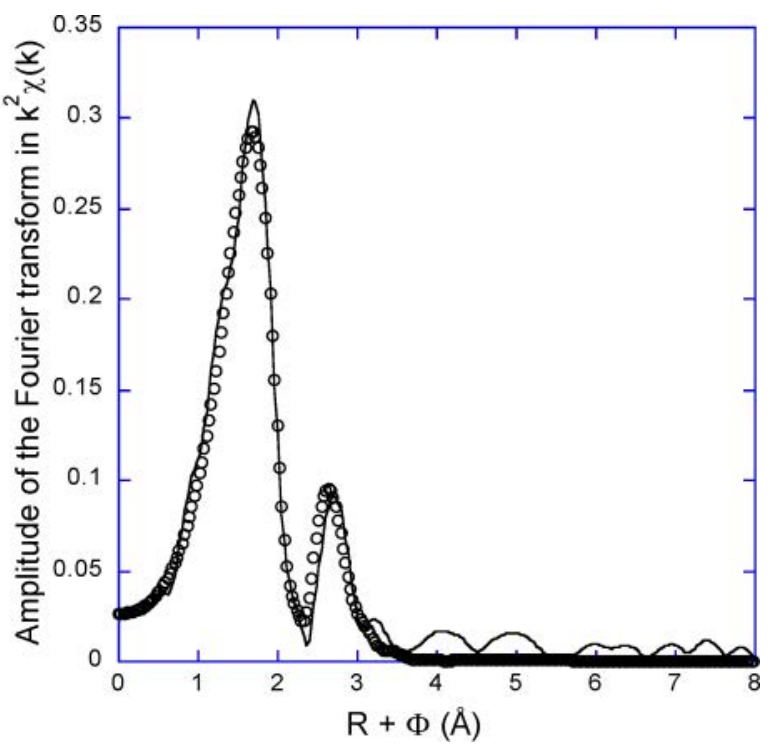

Figure 5. (left) EXAFS spectrum of Ag@ZSM-5 at the Ag K edge. Straight line, experimental; circles, fit. (right) Invert Fourier transform of the EXAFS spectrum of Ag@ZSM-5. Straight line, experimental; circles, fit. 
consequently the partial reduction of $\mathrm{Ag}^{+}$and formation of small metal nanoclusters of $\mathrm{Ag}^{0}$ with the possible concomitant presence of $A g_{n}^{m+}$ clusters. The formation of silver nanocluster was also observed by Agostini et $\mathrm{al}^{46}$ In their study, upon heating Ag-ETS-10 at $673 \mathrm{~K}$ (under inert atmosphere), the amplitude of the first contribution ( $\mathrm{Ag}-\mathrm{O}$ at $2.33 \AA$ ) decreases while the second contribution increases $(\mathrm{Ag}-\mathrm{Ag}$ at $2.7 \AA)$. This result confirms the formation of small nanoclusters due to the reduction of a fraction of the silver content. Both DebyeWaller factors are large (above $0.01 \AA^{2}$ ), which suggests a relatively disordered system (although we note that this value is in agreement with the Debye-Waller factors observed by Joyner et al. $^{47}$ for H@ZSM-5).

To further characterize the silver phase in Ag-loaded zeolites, the XANES spectrum of Ag@ZSM-5 has been recorded and compared to that of $\operatorname{Ag}(0)$ metal, $\mathrm{Ag}(\mathrm{II}) \mathrm{O}$, and $\mathrm{Ag}(\mathrm{I}) \mathrm{NO}_{3}$ (Figure $\mathrm{S} 1$ of the Supporting Information). The energy position of the XANES spectrum is related to the formal oxidation state of the cation, although this position may be modulated by the local symmetry. Nevertheless, XANES spectra have been used in a phenomenological way to assess the cation formal oxidation state. The comparison of XANES spectra suggests that Ag@ZSM-5 contains mainly charged species. Nevertheless, this interpretation must be taken with care because the resolution for the $\mathrm{Ag} \mathrm{K}$ edge is smeared by the core hole width (around $6 \mathrm{eV}$ for Ag 1s orbital). In summary, the XANES/EXAFS analysis suggests that Ag@ZSM-5 contains two distinct silver species: a fraction of silver is in cationic form such as cationic $\mathrm{Ag}^{+}$and/or charged clusters $\mathrm{Ag}_{{ }_{n}}{ }^{m+}$ while the other fraction is reduced to $\mathrm{Ag}^{0}$. This partial reduction is also confirmed by XRD analysis presented before. TEM analysis also confirms the formation of the nanoparticles on the zeolite surface.

3.3. Molecular Simulation. In order to clarify the experimental results above, we have carried out intensive molecular simulations of xenon adsorption on two distinct systems: (1) $\mathrm{Ag}(\mathrm{I}) @ Z S M-5$ (i.e., zeolite framework) with silver ion in exchange cationic position and (2) silver nanoparticles (with a FCC structure) with different sizes ranging from 1 to 4 $\mathrm{nm}$. Figure 6 shows the xenon adsorption isotherms at $303 \mathrm{~K}$
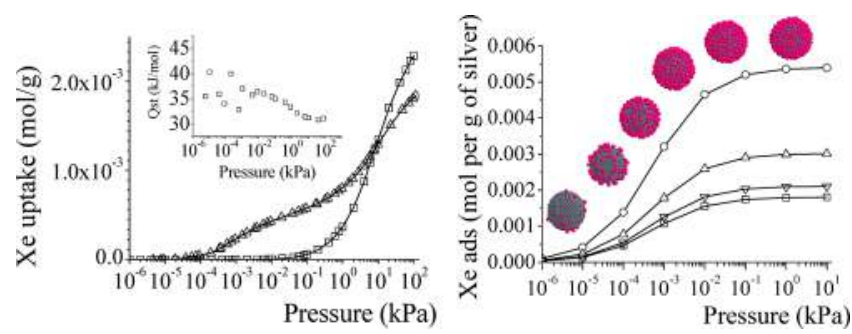

Figure 6. (left) Experimental $(\triangle)$ and simulated adsorption isotherms ( $\square)$ for xenon at $303 \mathrm{~K}$ on $\mathrm{Ag}(\mathrm{I}) @ Z S M-5$. The inset shows the corresponding isosteric heat of adsorption as estimated from the GCMC simulations. (right) Simulated adsorption isotherm of xenon on silver nanoparticles AgNPs $1(\bigcirc), 2(\triangle), 3(\nabla)$, and $4(\square) \mathrm{nm}$.

on $\mathrm{Ag}(\mathrm{I}) @ Z S M-5$ and AgNPS. In contrast to the experimental data, the xenon adsorption isotherm on model Ag(I)@ZSM-5 exhibits a single step and not two steps. At pressures lower than $10^{-1} \mathrm{kPa}$, the xenon adsorbed amount is close to zero, and the simulated data on model Ag(I)@ZSM-5 do not reproduce the experimental xenon uptake. Upon increasing the pressure, the two experimental and simulated adsorption isotherms are in good agreement. In addition, the calculated isosteric heat of adsorption (insert in Figure 6, left), around $-30--35 \mathrm{~kJ} / \mathrm{mol}$, is in agreement with the values estimated by modeling the experimental adsorption isotherm against the Langmuir model $(-34 \mathrm{~kJ} / \mathrm{mol})$ for the weak site (site I). ${ }^{18}$ However, the Ag(I)@ ZSM5 model does not describe accurately the whole experimental adsorption isotherm since the strongest adsorption sites, which are responsible for xenon adsorption at low pressure, are not observed. On the other hand, it represents quite well the weak adsorption sites in terms of number of sites and adsorption energy strength.

The simulated adsorption isotherms for xenon on silver nanoparticles (Figure 6, right) reveal that xenon gets adsorbed at very low pressures $\left(10^{-5} \mathrm{kPa}\right)$. Xenon adsorption on the AgNPs starts between $10^{-5}$ and $10^{-4} \mathrm{kPa}$, which is in good agreement with the experimental measurement for Ag@ZSM-5. The simulated isosteric heat of adsorption is in the range from -50 to $-65 \mathrm{~kJ} / \mathrm{mol}$, depending on the xenon coverage (molecular configuration shown in the inset of Figure 6, right). Such isosteric heats of adsorption together with the pressure at which adsorption starts suggest that adsorption at the nanoparticle surface corresponds to the strong adsorption site (site II) observed in the experimental data. The difference between the experimental and simulated heats of adsorption is thought to be due to the use of the Langmuir model in the treatment of the experimental data. Indeed, while this model reproduces very well the shape of the adsorption isotherm, it is based on some approximations such as the assumption of independent adsorption sites which lead to errors in the estimate of the heat of adsorption. As mentioned above, the molecular simulations allow calculating the isosteric heat of adsorption from the first xenon atoms adsorbed. The molecular simulations carried out for the two models (silver-exchanged zeolite and silver nanoparticles) suggest that adsorption at high pressure $(P>1 \mathrm{kPa})$ occurs in the zeolite framework, while adsorption at much lower pressures occurs on the silver nanoparticles. As a result, the latter could explain the large experimental isosteric heat of adsorption corresponding to the strong adsorption site (site II).

Figure 6 also shows typical molecular configurations of xenon adsorbed on silver nanoparticles at different pressures. Upon filling, xenon first gets adsorbed on the nanoparticle edges (from $10^{-6}$ to $10^{-4} \mathrm{kPa}$ ). Adsorption then occurs in a continuous fashion until the surface is uniformly covered by a xenon monolayer (from $10^{-3}$ to $10^{-2} \mathrm{kPa}$ ). The xenon adsorbed amount per unit of particle surface area is independent of the nanoparticle size (provided the particle is larger than 2-3 $\mathrm{nm}$ ).

3.4. Simple Model of Gas Adsorption on Composite Materials (Zeolite + Silver Nanoparticles). This section aims to estimate the proportion between $\mathrm{Ag}(\mathrm{I})$ and $\mathrm{Ag0}$ in Ag@ZSM-5. For this purpose, we have developed a simple model of gas adsorption on composite materials made up of silver-exchanged zeolites ( $\mathrm{Ag}(\mathrm{I}) @ Z \mathrm{ZSM}-5)$ and silver nanoparticles adsorbed at the external zeolite surface. In what follows, we derive a simple equation which allows describing adsorption on such systems and test it against molecular simulations. We also apply it to our experimental data and show that it allows retrieving the nanoparticle size distribution seen from TEM experiments. Finally, we further validate this model by showing that it also allows predicting krypton adsorption on the same system (although no data from krypton adsorption was used to derive the model). 
In order to describe the adsorption isotherm on a system composed of silver nanoparticles adsorbed at the external surface of the zeolite, we write that the system contains $x_{\mathrm{Ag} @ \mathrm{ZSM}-5}$ unit cells of Ag@ZSM-5, $x_{\mathrm{H}-\mathrm{ZSM}-5}$ unit cells of $\mathrm{H}$ ZSM-5, and silver particles with a size distribution $l(r)$. The $x_{\mathrm{H}-\mathrm{ZSM}-5}$ unit cell of H-ZSM-5 arises from the fact that all silver cations which are reduced when forming a silver nanoparticle are replaced by hydrogen atoms within the zeolite framework. Let $f(P)$ and $g(P)$ be the Xe adsorption isotherms in Ag@ZSM5 and the H-ZSM-5 unit cell, respectively. $h(P, r)$ is the Xe adsorption isotherm on a silver nanoparticle of a size $r$. The xenon adsorbed amount $n(P)$ at a pressure $P$ is therefore the sum of three contributions: (1) adsorbed amount in the silverexchanged zeolite Ag(I)@ZSM-5, (2) adsorbed amount on the silver nanoparticles AgNPS, and (3) adsorbed amount in the $\mathrm{H}^{+}$-exchanged zeolite H@ZSM-5:

$$
\begin{aligned}
n(P)= & x_{\mathrm{Ag} @ Z S M-5} f(P)+x_{\mathrm{H}-\mathrm{ZSM}-5} g(P) \\
& +\int l(r) h(P, r) \mathrm{d} r
\end{aligned}
$$

The first two terms in eq 3, which corresponds to xenon adsorption on Ag(I)@ZSM-5 and H@ZSM-5, accounts for adsorption at high pressure on zeolite. The last term in eq 3 describes adsorption at low pressure on the silver nanoparticles using a nanoparticle size distribution $l(r)$. In order to determine $h(P, r)$, xenon adsorption on silver nanoparticles was predicted using GCMC simulations for particle sizes ranging from 0.25 to $8 \mathrm{~nm}$ (details can be found in the Supporting Information).

In order to validate our model prior to applying it to experimental data, we have first simulated xenon adsorption isotherm on a model system consisting of a nanoparticle located at the external surface of a zeolite membrane (model (3), Figure 1). As shown in Figure S4 of the Supporting Information, the adsorption isotherm predicted using eq 3 is in good agreement with the simulated xenon adsorption isotherm (we note that no adjustable parameters are needed since all terms in eq 3 are known for the simulated composite system). This result validates our model together with the hypothesis that xenon adsorption occurs independently (i.e., in different pressure ranges) on the zeolite framework and on the silver particles.

Figure 7 shows a fit of the experimental xenon adsorption isotherm at $303 \mathrm{~K}$ against eq 3 (a Gaussian distribution was assumed for the particle size distribution). The simulated adsorption isotherm predicted by eq 3 is in good agreement with the experimental data. The small difference between the two adsorption isotherms is due to the approximations used in
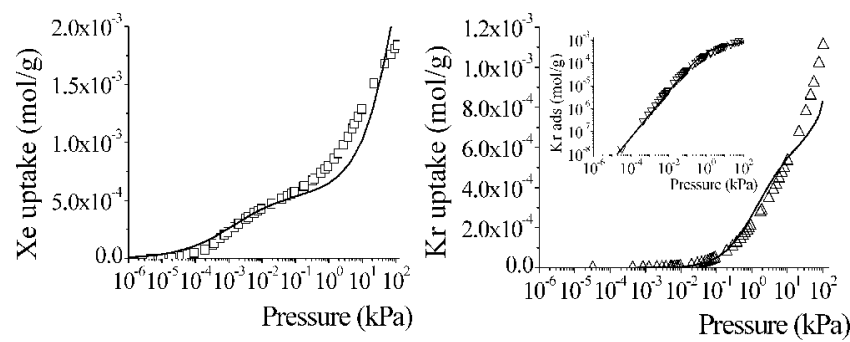

Figure 7. (left) Xenon adsorption isotherm at $303 \mathrm{~K}$ on Ag@ZSM-5: experimental (symbols), model corresponding to eq 3 (line). (right) Experimental $\mathrm{Kr}$ adsorption isotherm at $303 \mathrm{~K}$ on Ag@ZSM-5: experimental (symbols), model corresponding to eq 3 (line). the model: (1) silver nanoparticles without oxide phase, (2) replacement of silver reduced by hydrogen to ensure the electroneutrality of the simulation box, and (3) ideal framework without any defects. The parameters extracted from the fit of eq 3 against the experimental data are shown in Table 3 together

Table 3. Comparison of Experimental Parameters with Those Extracted from eq 3

\begin{tabular}{lll} 
& \multicolumn{1}{c}{ experiments } & \multicolumn{1}{c}{ simulation } \\
Mean particle size distribution & $3 \mathrm{~nm}$ & $1 \mathrm{~nm}$ \\
$\sigma$ (standard deviation) & 0.8 & 0.25 \\
$\%$ Ag loaded & $10.5-11 \%$ & $12.5 \%$ \\
$\mathrm{Ratio} \mathrm{Xe} \mathrm{strong} \mathrm{site} / \mathrm{Ag}_{\mathrm{Ag}^{0} / \mathrm{Ag}_{\text {(loaded) }}}$ & $1 \mathrm{Xe}$ for $\sim 2 \mathrm{Ag}$ & $1 \mathrm{Xe}$ for $\sim 1.7 \mathrm{Ag}$ \\
& $/$ & 0.8
\end{tabular}

${ }^{a} \mathrm{Ag} 0 / \mathrm{Ag}($ loaded $)$ is the ratio of the amount of reduced $\mathrm{Ag}(\mathrm{Ag} 0)$ and the total amount of silver in the sample.

with available experimental parameters. The percentage of silver in the zeolite in our model (12.5 wt \%) is in very good agreement with the experimental value (10.5-11wt \%). Moreover, the mean particle size centered around a value of $1 \mathrm{~nm}$, as obtained from our model, is lower than the value estimated from TEM ( $3 \mathrm{~nm})$. The error may be due to the ability of the GCMC molecular simulations to describe Xe adsorption on silver particles. We estimated a database of xenon adsorption isotherms on silver particles as a function of the particles size (see details in the Supporting Information). While the simulated data for independent silver nanoparticles introduce an error in the modeling of the adsorption isotherm for the experimental system, we believe that the differences between the simulated and experimental particles size distributions are mainly due to the fact that the resolution of the TEM images is not sufficient to see very small nanoparticles $(\sim \mathrm{nm})$. As a result, the experimental particle size distribution necessarily overestimates the average particle size. In a study on the formation of silver clusters in Ag@ZSM-5 by electron beam irradiation, Sasaki et al. ${ }^{51}$ estimated that silver clusters are composed of 60-90 atoms. Such a value, which corresponds to a size of about $1.25 \mathrm{~nm}$, is in excellent agreement with our prediction based on eq 3. Overall, the results and data above suggest that our model reasonably captures Xe adsorption on composite systems made up of silver nanoparticles and Agexchanged zeolites.

If we consider adsorption on silver nanoparticles only, we observe a saturation of the xenon adsorbed amount on AgNPs at around $10^{-1} \mathrm{kPa}$. On the basis of eq 3 , the maximum xenon adsorbed amounts are close to $5.5 \times 10^{-4} \mathrm{~mol}(\mathrm{Xe}) \mathrm{g}^{-1}$. The quantities of silver reduced in the metallic form $\left(\mathrm{Ag}^{+} \rightarrow\right.$ AgNPs) extracted from eq 3 is around $9.4 \times 10^{-4} \mathrm{~mol}(\mathrm{Ag}) \mathrm{g}^{-1}$. Considering the AgNPs as the only strong sites, the ratio of the total xenon adsorbed amount on the strong site and the amount of reduced silver atoms (i.e., AgNPS) is equal to 1.7 (i.e., at the maximum adsorption on the strong site, $1 \mathrm{Xe}$ atom is adsorbed for 1.7 silver). This value is in good agreement with the experimental value of 2 determined by Daniel et al. ${ }^{18}$ On the basis of the assumption that a fraction of surface atoms around $40 \%$ of AgNPs corresponding to the particle size distribution observed in TEM (Figure 3), the adsorbed Xesurface silver ratio would be around 1:1. This ratio is close to the value determined by eq 3 , which is around 0.9:1 for the $\mathrm{Xe}$-surface silver ratio. As discussed above, the ratio between the numbers of silver atoms reduced $\mathrm{Ag}^{0}$ and silver cations $\mathrm{Ag}^{+}$ 
is difficult to estimate from experiments (XANES). In contrast, the model presented in this paper provides a simple tool to estimate such a ratio.

To further validate our model, we applied eq 3 to krypton adsorption on Ag@ZSM-5. As mentioned in Introduction, the choice of krypton and xenon was motivated by the fact that separation of rare gases is a key step in the monitoring of radioactive xenon to detect illegal nuclear activities. We note that the comparison between our model and the experimental krypton adsorption data is a severe validation procedure as no parameters were derived from the experimental data. Figure 7 compares the krypton adsorption isotherm on silver-exchanged ZSM-5 with the predictions from eq 3 . A very good agreement between the experimental data and theoretical predictions is observed. This further confirms that adsorption on silverloaded ZSM-5 consists of adsorption at low pressure on silver nanoparticles followed by adsorption in ZSM-5 at higher pressure. In previous work, Grosse et al. ${ }^{19,52}$ characterized the strong interaction between xenon and silver-exchanged zeolite by means of ${ }^{129} \mathrm{Xe}$ NMR. These authors concluded that xenon interacts with a charged molecule which corresponds to silver cation. The results reported in the present work show that xenon is more strongly adsorbed on silver nanoparticles. These two possible scenarios are not necessarily contradictory since both mechanisms occur at different pressure ranges. The NMR studies were carried out at pressure higher than $1 \mathrm{kPa}$ where $\mathrm{Ag}^{0}-\mathrm{Xe}$ interactions are masked by the $\mathrm{Ag}^{+}-\mathrm{Xe}$ interactions (indeed, in this pressure range, adsorption on the silver cluster is already complete and further adsorption occurs on the $\mathrm{Ag}^{+}$ cations). ${ }^{20,53}$ The presence of silver nanoparticles, as taken into account in our model, is in full agreement with TEM, XRD, and EXAFS. The main information extracted in this work is that xenon at low pressures is preferentially adsorbed on the silver aggregate and particles than on the silver cations. Finally, experimental adsorption on Na@ZSM-5 and Ag@ZSM-5 shows different xenon adsorbed amounts at high pressure $(100 \mathrm{kPa})$ which exactly correspond to the xenon loaded on the strong site (results not shown). This results further supports the idea that silver nanoparticles, which are responsible for the strong adsorption sites, form on the external surface of the zeolite host.

\section{CONCLUSION}

This work deals with xenon adsorption on silver-exchanged zeolites. The GCMC simulations suggest that the specific interaction between xenon and silver-exchanged zeolite observed at low pressure is due to the presence of silver nanoparticles located at the external surface of the zeolite grains.

This paper also reports a simple model which allows characterizing and predicting adsorption of gases on hybrid systems made up of nanoparticles deposited at the external surface of porous solids. This idea is fully consistent with previous works in which it was shown that adsorption in materials with different porosities and surface areas can be described using a linear combination of adsorption in the different regions. ${ }^{54,55}$ This model shows that adsorption of a simple gas can be used to characterize the nanoparticle size distributions, dispersion, and amounts of reduced silver. Moreover, provided these parameters are known, this simple model allows predicting adsorption of other gases.

\section{ASSOCIATED CONTENT}

\section{Supporting Information}

XANES data, xenon adsorption on silver nanoparticles, validation of the linear combination technique, typical molecular configurations, and adsorption isotherms. This material is available free of charge via the Internet at http:// pubs.acs.org.

\section{AUTHOR INFORMATION}

\section{Corresponding Authors}

E-mail: sylvain.topin@cea.fr. Tel: +33 469265452.

E-mail: coasne@mit.edu. Tel: +1 6173244357.

\section{Notes}

The authors declare no competing financial interest.

\section{ACKNOWLEDGMENTS}

We thank IRCELYON Scientific Services for sample characterization using ICP-OES and TEM. We also acknowledge CEA/ Le Ripault for their help with the XRD analysis. We also thank Dr. Thomas TAFFARY for his help. XAS measurements were performed at SOLEIL in the frame of in-house project 99130072.

\section{REFERENCES}

(1) Dubasov, Y. V.; Popov, Y. S.; Prelovskii, V. V.; Donets, A. Y.; Kazarinov, N. M.; Mishurinskii, V. V.; Popov, V. Y.; Rykov, Y. M.; Skirda, N. V. The APIKC-01 Automatic Facility for Measuring Concentrations of Radioactive Xenon Isotopes in the Atmosphere. Instrum. Exp. Tech. 2005, 48, 373-379.

(2) Cullen, S. C.; Gross, E. G. The Anesthetic Properties of Xenon in Animals and Human Beings, with Additional Observations on Krypton. Science 1951, 113, 580-582.

(3) Fraissard, J.; Ito, T. 129Xe N.M.R. Study of Adsorbed Xenon: A New Method for Studying Zeolites and Metal-Zeolites. Zeolites 1988, $8,350-361$.

(4) Fontaine, J. P.; Pointurier, F.; Blanchard, X.; Taffary, T. Atmospheric Xenon Radioactive Isotope Monitoring. J. Environ. Radioact. 2004, 72, 129-135.

(5) Auer, M.; Axelsson, A.; Blanchard, X.; Bowyer, T. W.; Brachet, G.; Bulowski, I.; Dubasov, Y.; Elmgren, K.; Fontaine, J. P.; Harms, W.; et al. Intercomparison Experiments of Systems for the Measurement of Xenon Radionuclides in the Atmosphere. Appl. Radiat. Isot. 2004, 60, 863-877.

(6) Stocki, T. J.; Blanchard, X.; D’Amours, R.; Ungar, R. K.; Fontaine, J. P.; Sohier, M.; Bean, M.; Taffary, T.; Racine, J.; Tracy, B. L.; et al. Automated Radioxenon Monitoring for the Comprehensive NuclearTest-Ban Treaty in Two Distinctive Locations: Ottawa and Tahiti. J. Environ. Radioact. 2005, 80, 305-326.

(7) Prelovskii, V. V.; Kazarinov, N. M.; Donets, A. Y.; Popov, V. Y.; Popov, I. Y.; Skirda, N. V. The ARIX-03F Mobile Semiautomatic Facility for Measuring Low Concentrations of Radioactive Xenon Isotopes in Air and Subsoil Gas. Instrum. Exp. Technol. 2007, 50, 393397.

(8) Ringbom, A.; Larson, T.; Axelsson, A.; Elmgren, K.; Johansson, C. SAUNA: A System for Automatic Sampling, Processing, and Analysis of Radioactive Xenon. Nucl. Instrum. Methods Phys. Res., Sect. A 2003, 508, 542-553.

(9) Barrer, R. M.; Davies, J. M. Sorption in Decationated Zeolites. I. Gases in Hydrogen-Chabazite. Proc. R. Soc. London, Ser. A 1970, 320, 289-308.

(10) Barrer, R. M.; Papadopoulos, R. The Sorption of Krypton and Xenon in Zeolites at High Pressures and Temperatures. I. Chabazite. Proc. R. Soc. London, Ser. A 1972, 326, 315-330.

(11) Barrer, R. M.; Papadopoulos, R.; Ramsay, J. D. F. The Sorption of Krypton and Xenon in Zeolites at High Pressures and Temper- 
atures. II. Comparison and Analysis. Proc. R. Soc. London, Ser. A 1972, $326,331-345$.

(12) Munakata, K.; Kanjo, S.; Yamastuki, S.; Koga, A.; Ianovski, D. Adsorption of Noble Gases on Silver-Mordenite. J. Nucl. Sci. Technol. 2003, 40, 695-697.

(13) Munakata, K.; Fukumatsu, T.; Yamatsuki, S.; Tanaka, K.; Nishikawa, M. Adsorption Equilibria of Krypton, Xenon, Nitrogen and Their Mixtures on Molecular Sieve 5A and Activated Charcoal. J. Nucl. Sci. Technol. 1999, 36, 818-829.

(14) Watermann, J.; Boddenberg, B. Isosteric Heats of Adsorption of Xenon in Silver-Exchanged Y Zeolites. Zeolites 1993, 13, 427-429.

(15) Saxton, C. G.; Kruth, A.; Castro, M.; Wright, P. A.; Howe, R. F. Xenon Adsorption in Synthetic Chabazite Zeolites. Microporous Mesoporous Mater. 2010, 129, 68-73.

(16) Kuznicki, S. M.; Anson, A.; Koenig, A.; Kuznicki, T. M.; Haastrup, T. Xenon Adsorption on Modified ETS-10. J. Phys. Chem. C 2007, 111, 1560-1562.

(17) Fujie, K.; Nakamura, A.; Hidano, T.; Kuroda, Y.; Mori, T.; Torigoe, H. Xenon Adsorbent, Xenon Enrichment Method, Xenon Enrichment Device, and Air Liquefaction and Separation Device. Patent WO2010021127, 2010.

(18) Daniel, C.; Elbaraoui, A.; Aguado, S.; Springuel-Huet, M. A.; Nossov, A.; Fontaine, J. P.; Topin, S.; Taffary, T.; Deliere, L.; Schuurman, Y.; et al. Xenon Capture on Silver-Loaded Zeolites: Characterization of a Very Strong Adsorption Sites. J. Phys. Chem. C 2013, 117, 15122-15129.

(19) Grosse, R.; Gedeon, A.; Watermann, J.; Fraissard, J.; Boddenberg, B. Adsorption and 129Xe N.M.R of Xenon in SilverExchanged Y Zeolites: Application to the Location of Silver Cations. Zeolites 1992, 12, 909-915.

(20) Gedeon, A.; Burmeister, R.; Grosse, R.; Boddenberg, B.; Fraissard, J. 129Xe NMR for the Study of Oxidized and Reduced AgX Zeolites. Chem. Phys. Lett. 1991, 179, 191-194.

(21) Nguyen, H. G.; Konya, G.; Eyring, E. M.; Hunter, D. B.; Truong, T. N. Theoretical Study on the Interaction between Xenon and Positively Charged Silver Clusters in Gas Phase and on the (001) Chabazite Surface. J. Phys. Chem. C 2009, 113, 12818-12825.

(22) Shi, C.; Cheng, M.; Qu, Z.; Bao, X. On The Correlation between Microstructural Changes of Ag-H-ZSM-5 Catalysts and Their Catalytic Performances in the Selective Catalytic Reduction of NOx by Methane. J. Mol. Catal. A: Chem. 2005, 235, 35-43.

(23) Tsutsumi, K.; Takahashi, H. The Formation of Metallic Silver in Silver-Form Zeolites. Bull. Chem. Soc. Jpn. 1972, 45, 2332-2337.

(24) Seoung, D.; Lee, Y.; Cynn, H.; Park, C.; Choi, K. Y.; Blom, D. A.; Evans, W. J.; Kao, C. C.; Vogt, T.; Lee, Y. Irreversible Xenon Insertion Into a Small-Pore Zeolite at Moderate Pressures and Temperatures. Nat. Chem. 2014, 6, 835-839.

(25) Liu, J.; Strachan, D. M.; Thallapally, K. Enhanced Noble Gas Adsorption in Ag@MOF-74Ni. Chem. Commun. 2014, 50, 466-468.

(26) Sitaud, B.; Solari, P. L.; Schlutig, S.; Llorens, I.; Hermange, H. Characterization of Radioactive Materials using the MARS Beamline at the Synchrotron SOLEIL. J. Nucl. Mater. 2012, 425, 238-243.

(27) Ravel, B.; Newville, M. ATHENA, ARTEMIS, HEPHAESTUS:

Data Analysis for X-Ray Absorption Spectroscopy using IFEFFIT. J. Synchrotron Rad. 2005, 12, 537-541.

(28) Rehr, J. J.; Albers, R. C. Theoretical Approaches to X-Ray Absorption Fine Structure. Rev. Mod. Phys. 2000, 72, 621-654.

(29) Rasband, W. S. Imagej; National Institutes of Health: Bethesda, Maryland, http://imagej.nih.gov/ij/, 1997-2014.

(30) Abrioux, C.; Coasne, B.; Maurin, G.; Henn, F.; Boutin, A.; Di Lella, A.; Nieto-Draghi, C.; Fuchs, A. H. A Molecular Simulation Study of the Distribution of Cation in Zeolites. Adsorption 2008, 14, 743754.

(31) Lowenstein, W. The Distribution of $\mathrm{Al}$ in the Tetrahedra of Silicates and Aluminates. Am. Mineral. 1954, 39, 92-96.

(32) Catlow, C. R. A.; Freemen, C. M.; Vessal, B.; Tomlinson, S. M.; Leslie, M. Molecular Dynamics of Hydrocarbon Diffusion in Zeolites. J. Chem. Soc., Faraday Trans. 1991, 87, 1947-1950.
(33) Van Beest, B. W. H.; Kramer, G. J.; Van Santen, R. A. Force Fields for Silica and Aluminophosphates Based on $\mathrm{Ab}$ Initio Calculations. Phys. Rev. Lett. 1990, 64, 1955-1958.

(34) Frenkel, D.; Smit, B. Understanding Molecular Simulation: From Algorithms to Applications, 2nd ed.; Academic press: London, 2002.

(35) Skoulidas, A. I.; Sholl, D. S. Transport Diffusivities of CH4, $\mathrm{CF} 6, \mathrm{He}, \mathrm{Ne}, \mathrm{Ar}, \mathrm{Xe}$ and SF6 in Silicalite from Atomistic Simulations. J. Phys. Chem. B 2002, 106, 5058-5067.

(36) Pickett, S. D.; Nowak, A. K.; Thomas, J. M.; Peterson, B. K.; Swift, J. F. P.; Cheetham, A. K.; den Ouden, C. J. J.; Smit, B.; Post, M. F. M. Mobility of Adsorbed Species in Zeolites: A Molecular Dynamics Simulation of Xenon in Silicalite. J. Phys. Chem. 1990, 94, 1233-1236.

(37) Haynes, W. M. Polarizabilities of Atoms and Ions in Solids. In HandBook of Chemistry and Physics, 95th ed.; CRC Press: Taylor and Francis, 2014.

(38) Pellenq, R. J. M.; Nicholson, D. Grand Ensemble Monte Carlo Simulation of Simple Molecules Adsorbed in Silicalite-1 Zeolite. Langmuir 1995, 11, 1626-1635.

(39) Berthelot, D. Sur le Mélange des Gaz. C. R. Hebd. Seances Acad. Sci. 1898, 126, 1703-1855.

(40) Lorentz, H. A. Ueber die Anwendung des Satzes vom Virial in der Kinetischen Theorie der Gase. Ann. Phys. 1881, 248, 127-136.

(41) Timpel, D.; Scheerschimdt, K.; Garofalini, S. H. Silver Clustering in Sodium Silicate Glasses: A Molecular Dynamics Study. J. Non-Cryst. Solids 1997, 221, 187-198.

(42) Mayo, S. L.; Olafson, B. D.; Goddard, W. A. DREIDING: A Generic Force Field for Molecular Simulations. J. Phys. Chem. 1990, 94, 8897-8909.

(43) Nicholson, D.; Parsonage, N. G. Computer Simulation and the Statistical Mechanical Theory of Adsorption; Academic Press: London, 1982.

(44) Nguyen, C.; Do, D. D. Dual Langmuir Kinetic Model for Adsorption in Carbon Molecular Sieve Materials. Langmuir 2000, 16, $1868-1873$.

(45) Bordiga, S.; Lamberti, C.; Turnes Palomino, G.; Geobaldo, F.; Arduino, D.; Zecchina, A. Nitrosylic Complexes in Ag(I)-ZSM-5: A Comparison with Cu(I)-ZSM-5. Microporous Mesoporous Mater. 1999, 30, 129-135.

(46) Agostini, G.; Usseglio, S.; Groppo, E.; Uddin, M. J.; Prestipino, C.; Bordiga, S.; Zecchina, A.; Solari, P. L.; Lamberti, C. From Isolated $\mathrm{Ag}+$ Ions to Aggregated Ag0 Nanoclusters in Silver-Exchanged Engelhard Titanosilicate (ETS-10) Molecular Sieve: Reversible Behavior. Chem. Mater. 2009, 21, 1343-1353.

(47) Joyner, R. W.; Smith, A. D.; Stockenhuber, M.; Van Den Berg, M. W. E. A Soft X-ray EXAFS Study of the Local Structure of Tetrahedral Aluminum in Zeolites. In Studies in Surface Science and Catalysis; Elsevier Science BV: Amsterdam, 2004; pp 1406-1410.

(48) Hecht, D.; Borthen, P.; Strehblow, H. H. In Situ Examination of Anodic Silver Oxide Films by EXAFS in the Reflection Mode. J. Electroanal. Chem. 1995, 381, 113-121.

(49) Mansour, A. N. Evidence for an $\mathrm{Ag}_{4} \mathrm{O}_{3}$ Phase of Silver Oxide. J. Phys. Chem. 1990, 94, 1006-1010.

(50) Wyckoff, R. W. G. Crystal Structures, 2nd ed.; Interscience: New York, 1963; Vol. 1.

(51) Sasaki, Y.; Suzuki, T. Formation of Ag Cluster by Electron Beam Irradiation of Ag-Zeolites. Mater. Trans. 2009, 50, 1050-1053.

(52) Grosse, R.; Burmeister, R.; Boddenberg, B.; Gedeon, A.; Fraissard, J. Xenon-129 NMR of Silver Exchanged X- and Y-Type Zeolite. J. Phys. Chem. 1991, 95, 2443-2447.

(53) Gedeon, A.; Fraissard, J. 129Xe NMR of AgX, CuX, ZnX and CdX Zeolites. Comparative Study of nd10 Element-Xenon Interactions. Chem. Phys. Lett. 1994, 219, 440-444.

(54) Coasne, B.; Galarneau, A.; Gerardin, C.; Fajula, F.; Villemot, F. Molecular Simulation of Adsorption and Transport in Hierarchical Porous Materials. Langmuir 2013, 29, 7864-7875.

(55) Villemot, F.; Galarneau, A.; Coasne, B. Adsorption and Dynamics in Hierarchical Metal Organic Frameworks. J. Phys. Chem. C 2014, 118, 7423-7433. 